Article

\title{
Preparation of Porous Carbon Nanofibers with Tailored Porosity for Electrochemical Capacitor Electrodes
}

\author{
Jisu Kim ${ }^{1}$, Youn-Ji Heo ${ }^{2}$, Jin-Yong Hong ${ }^{2, *}$ and Sung-Kon Kim ${ }^{1,3, * \mathbb{D}}$ \\ 1 School of Semiconductor and Chemical Engineering, Jeonbuk National University, 567 Baekje-daero, \\ Deokjin-gu, Jeonju-si, Jeollabuk-do 54896, Korea; okjisu@naver.com \\ 2 Carbon Industry Frontier Research Center, Korea Research Institute of Chemical Technology (KRICT), \\ Daejeon 34114, Korea; yjheo@krict.re.kr \\ 3 School of Chemical Engineering, Jeonbuk National University, 567 Baekje-daero, Deokjin-gu, Jeonju-si, \\ Jeollabuk-do 54896, Korea \\ * Correspondence: jyhong@krict.re.kr (J.-Y.H.); skkim@jbnu.ac.kr (S.-K.K.)
}

Received: 2 January 2020; Accepted: 2 February 2020; Published: 5 February 2020

\begin{abstract}
Porous carbon electrodes that accumulate charges at the electrode/electrolyte interface have been extensively investigated for use as electrochemical capacitor (EC) electrodes because of their great attributes for driving high-performance energy storage. Here, we report porous carbon nanofibers (p-CNFs) for EC electrodes made by the formation of a composite of monodisperse silica nanoparticles and polyacrylonitrile (PAN), oxidation/carbonization of the composite, and then silica etching. The pore features are controlled by changing the weight ratio of PAN to silica nanoparticles. The electrochemical performances of p-CNF as an electrode are estimated by measuring cyclic voltammetry and galvanostatic charge/discharge. Particularly, the p-CNF electrode shows exceptional areal capacitance ( $13 \mathrm{mF} \mathrm{cm}^{-2}$ at a current of $\left.0.5 \mathrm{~mA} \mathrm{~cm}{ }^{-2}\right)$, good rate-retention capability $(\sim 98 \%$ retention of low-current capacitance), and long-term cycle stability for at least 5000 charge/discharge cycles. Based on the results, we believe that this electrode has potential for use as high-performance EC electrodes.
\end{abstract}

Keywords: electrochemical capacitor; energy storage; carbon nanofiber; porosity; polyacrylonitrile

\section{Introduction}

Among the different kinds of energy storage devices, electrochemical capacitors (ECs), also termed supercapacitors, are creating new opportunities in applications in which high power, fast charge/discharge, and long-lasting operation are needed [1-5], because energy for ECs can be stored as the charge accumulates on the electrode surface. For high energy and power, a significant electrical conductivity and high surface area are required for electrode materials. In spite of these advantages, the relatively small energy density of ECs over those of conventional rechargeable batteries limits their commercial utilization [6-10]. In this regard, advances in high-energy ECs have been devoted toward the preparation of highly efficient electrodes that are a determinant of electrochemical performances [11,12]. A number of notable examples in electrode materials have been created using porous carbon nanomaterials, while maintaining their intrinsic attributes. Particularly, nanostructuring of the pores of carbon nanomaterials is significant for fast mass transports, and ion diffusion through the pores can greatly improve electrochemical reactions at the electrode/electrolyte interface [13-16]. Three-dimensional (3D) porous nanoarchitecture have been created, in which pores and active materials are interconnected, leading to fast movements for both ions and electrons [17-20]. Porous nanostructures have been commonly created through self-assembly or template-assisted 
strategies [21-23]. For self-assembly, difficulties have been encountered in forming a well-organized pore network in electrodes [24,25]. Pores are randomly distributed, sometimes not well-interconnected, and vary in size, and self-assembly is induced by randomly aggregating carbon nanomaterials [26-29]. This structure could possibly induce large ohmic resistance and incomplete wetting of electrodes by electrolytes, leading to a large voltage drop at high currents [30-32]. In one successful example of template-assisted methods, Choi et al. prepared 3D microporous, chemically modified graphene starting with polystyrene colloids as a sacrificial template [19]. When graphene was initially used as the electrode materials for a supercapacitor in the form of packed (or dense) film, the electrochemical performance was not significant because the electrical double layer (EDL) between the electrode and electrolyte was not well made. However, as graphene was made in a 3D structure, the pores were notably formed. This affects the diffusional (or mass transport) behavior of electrochemical systems and provides significant EDLs, which are important for capacitance, rate-dependent capability, and energy and power densities. As such, the development of a well-organized porous structure is highly desirable, yet very challenging.

One-dimensional (1D) structured carbon materials are advantageous to charge carrier mobility along the axial direction, offering the potential of being used in energy storage [33]. However, low the capacitance and energy density of 1D carbon electrodes, due to the difficulties of their pore size/size distribution controls, should be improved for practical applications [34-38]. Recently, studies on 1D carbon materials have been particularly driven toward the fabrication of highly porous structures with controlled pore size distributions.

Here we report nanoporous carbon nanofibers prepared by the carbonization of electrospun polyacrylonitrile (PAN), embedding monodisperse silica nanoparticles as a sacrificial template [39,40]. The chemical etching of the silica enables a nanoporous structure to form without affecting the electronic properties of PAN-based carbon nanofibers. Such a 3D porous network structure provides a facilitated transport path for electrolyte ions and electrons [41].

\section{Materials and Methods}

\subsection{Materials}

Polyacrylonitile (PAN, $\mathrm{M}_{\mathrm{w}}=150,000 \mathrm{~g} \mathrm{~mol}^{-1}$ ), N,N-Dimethylformamide (DMF, $\geq 99.8 \%$, $\mathrm{M}_{\mathrm{w}}=73.09 \mathrm{~g} \mathrm{~mol}^{-1}$ ) and tetraethyl orthosilicate (TEOS, $98 \%, \mathrm{M}_{\mathrm{w}}=208.33 \mathrm{~g} \mathrm{~mol}^{-1}$ ) were supplied by Sigma-Aldrich (Korea). Hydrofluoric acid (HF, $\mathrm{M}_{\mathrm{w}}=20.01 \mathrm{~g} \mathrm{~mol}^{-1}$ ) was supplied by J.T. Baker. Ammonium hydroxide solution $\left(\mathrm{NH}_{4} \mathrm{OH}, 28.0-30.0 \%, \mathrm{M}_{\mathrm{w}}=35.05 \mathrm{~g} \mathrm{~mol}^{-1}\right)$ was supplied by SAMCHUN (Korea).

\subsection{Preparation of Porous Carbon Nanofibers}

Silica nanoparticles were synthesized using the Stöber method [42]. Silica nanoparticles (500 $\mathrm{wt} \%$ relative to polyacrylonitrile (PAN)) were mixed with $8 \mathrm{wt} \%$ PAN in DMF. The solution was stirred for $24 \mathrm{~h}$ at $50{ }^{\circ} \mathrm{C}$ and then ultrasonicated for $6 \mathrm{~h}$ at $50{ }^{\circ} \mathrm{C}$ to obtain a homogeneous solution. Composite nanofibers were produced via electrospinning. A $12-\mathrm{mL}$ syringe with a 23-gauge metal nozzle was used for electrospinning. A high voltage supplier was used to provide a varying voltage, of 11.0, 13.0, and $14.0 \mathrm{kV}$, to the syringe needle tip and a metal drum collector (NanoNC, Korea). The electrospun composite nanofibers were collected on a metal drum collector that was covered with aluminum foil at the feed rate at $10 \mu \mathrm{L} / \mathrm{min}$. The distance between the tip of the needle and the collector was $15 \mathrm{~cm}$. The resulting composite nanofibers were dried in a vacuum oven for $12 \mathrm{~h}$ at $70{ }^{\circ} \mathrm{C}$. Porous carbon nanofibers were formed by oxidation and subsequent carbonization of PAN/silica composite nanofibers. PAN/silica composite nanofibers were heated to $260{ }^{\circ} \mathrm{C}$ at a rate of $1{ }^{\circ} \mathrm{C} \mathrm{min}-1$ and held at that temperature for $3 \mathrm{~h}$ in an air atmosphere. Carbonization was performed by heating to $900{ }^{\circ} \mathrm{C}$ at a rate $2{ }^{\circ} \mathrm{C} \min ^{-1}$ in a $\mathrm{N}_{2}$ atmosphere and then the temperature was maintained for $3 \mathrm{~h}$. The carbonized 
composite nanofibers were soaked in $\mathrm{HF}$ for $6 \mathrm{~h}$ at $25^{\circ} \mathrm{C}$ to remove silica nanoparticles. The resulting porous carbon nanofibers were dried at room temperature.

\subsection{Characterization}

$\mathrm{N}_{2}$ adsorption/desorption isotherms were determined at $77.3 \mathrm{~K}$ using a surface area analyzer (ASAP 2420 V2.09K, Micromeritics, USA). Prior to measurements, the samples were preheated at $450{ }^{\circ} \mathrm{C}$ for $3 \mathrm{~h}$ under vacuum to remove any moisture or dust from within the pores of the samples. The Brunauer-Emmett-Teller (BET) model was used to calculate the specific surface area of the samples from the $\mathrm{N}_{2}$ adsorption isotherms in a relative pressure $\left(P / P_{0}\right)$ range of 0.02 to 0.06 . Surface and cross-section images of porous carbon nanofibers were acquired by field emission scanning electron microscopy (FE-SEM, Philips XL30S FEG, Netherlands) at magnifications of $\times 100$ to $\times 150 \mathrm{k}$, and at an accelerating voltage of 10 to $20 \mathrm{kV}$. Before observation, the samples were coated with a thin layer by spraying platinum (Pt) for $120 \mathrm{~s}$ using a Quorum Q 150T ES. Cyclic voltammetry $(\mathrm{CV})$, galvanostatic charge/discharge (GCD), and electrochemical impedance spectroscopy (EIS) were performed using an SP-200 potentiostat (Bio-Logic, Knoxville, TN, USA) in $1.0 \mathrm{M} \mathrm{H}_{2} \mathrm{SO}_{4}$ aqueous electrolyte in two-electrode mode at room temperature. The EIS test was conducted over the frequency range of $10^{6}$ to $10^{-2} \mathrm{~Hz}$ at the amplitude of the sinusoidal voltage by applying a $5-\mathrm{mV}$ signal. In the GCD profiles, the specific capacitance could be estimated using the following equation:

$$
\mathrm{C}=4 \mathrm{I} /[(\Delta \mathrm{V} / \Delta \mathrm{t}) \mathrm{A}]
$$

where $I$ is the current applied, $\Delta V / \Delta t$ is the slope of the discharge curve after the IR drop at the beginning of the discharge curve, and $A$ is the total area of two electrodes.

\section{Results and Discussion}

Porous carbon nanofibers (termed p-CNFs) were fabricated in four major steps: (1) electrospinning of polyacrylonitrile (PAN)/silica composite nanofibers; (2) oxidative stabilization at $260{ }^{\circ} \mathrm{C}$ in air; (3) carbonization at $900{ }^{\circ} \mathrm{C}$ under a nitrogen atmosphere; and (4) the removal of silica in a hydrogen fluoride aqueous solution for $6 \mathrm{~h}$ at room temperature (Figure 1).

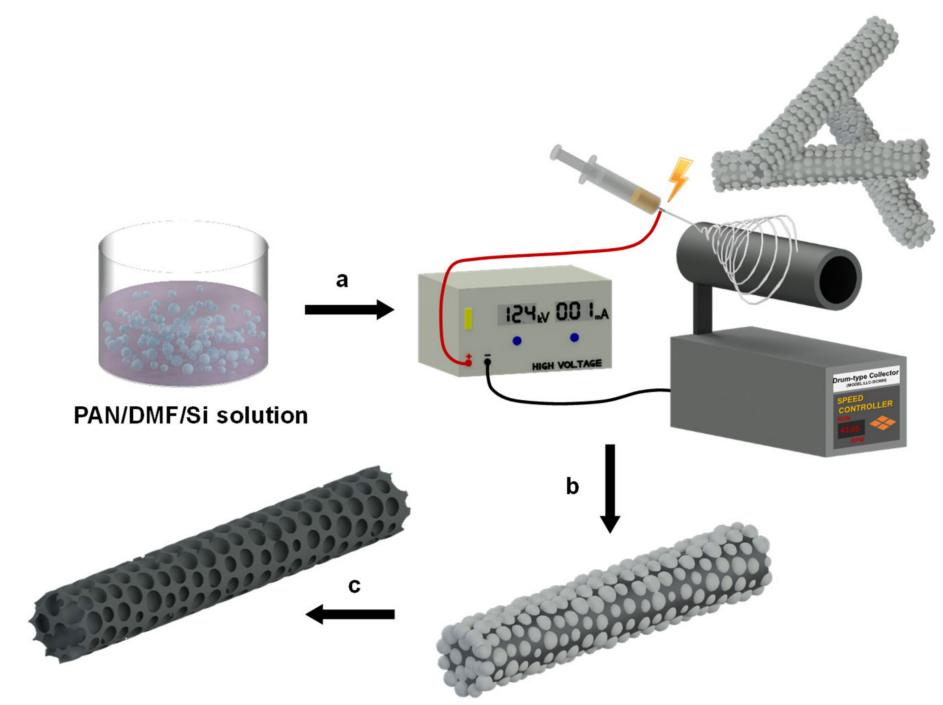

Figure 1. Schematic illustration of the fabrication process for porous carbon nanofibers (p-CNFs). The major steps of the fabrication process were: (a) Electrospinning the polyacrylonitrile (PAN)/silica solution using a metal drum collector. (b) Oxidation of the PAN/silica nanofibers in air at $260{ }^{\circ} \mathrm{C}$, then carbonization at $900{ }^{\circ} \mathrm{C}$ under a slow stream of nitrogen. (c) Removal of silica nanoparticles by immersing in hydrofluoric acid (HF) solution for $6 \mathrm{~h}$. 
Monodisperse silica nanoparticles were formed using the Stöber method [42]. The mean particle size of the silica was about $50 \mathrm{~nm}$, which was determined by SEM. Neat PAN-based CNFs were also prepared using the same protocol, except for the use of silica nanoparticles. Figure 2 shows the FE-SEM images of neat PAN-based CNF, electrospun PAN/silica-basis composite carbon nanofibers, and p-CNF. Well-distributed silica nanoparticles, which were fugitive, in PAN/silica composite carbon nanofibers left pores in $\mathrm{p}$-CNF after the silica etching process. As such, the $\mathrm{p}$-CNF had pores evenly distributed in the fibers. This was due to the good dispersion of the silica nanoparticles in the PAN solution. Fiber diameters ranging from 250 to $300 \mathrm{~nm}$ were preserved after the carbonization and etching processes.
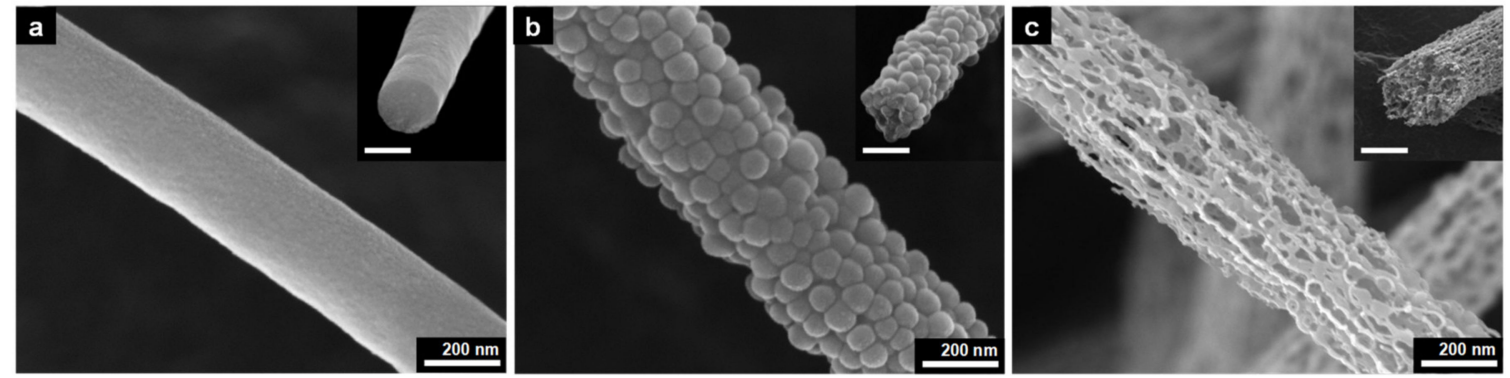

Figure 2. FE-SEM images of (a) neat CNF, (b) PAN/silica composite carbon nanofiber, and (c) p-CNF (insets: cross-sectional SEM images, scale bars $=200 \mathrm{~nm}$ ).

Porosity of the $\mathrm{p}-\mathrm{CNF}$ was adjusted by changing the $\mathrm{wt} \%$ of silica nanoparticles to PAN ranging from 350 to $700 \mathrm{wt} \%$ because it depended on the amounts of silica nanoparticles that adhered to the CNF surface. Figure 3 shows FE-SEM images of p-CNFs prepared using different silica nanoparticles contents. Not surprisingly, the porosity of the p-CNFs increased by increasing the content of silica nanoparticles from 350 to $500 \mathrm{wt} \%$. No significant change in porosity of $\mathrm{p}$-CNF was observed when $750 \mathrm{wt} \%$ of silica nanoparticles were added to the PAN solution when compared to $500 \mathrm{wt} \%$ silica content. Accordingly, we limited the discussion here to $\mathrm{p}-\mathrm{CNF}$ prepared by using PAN solution with $500 \mathrm{wt} \%$ silica nanoparticles.
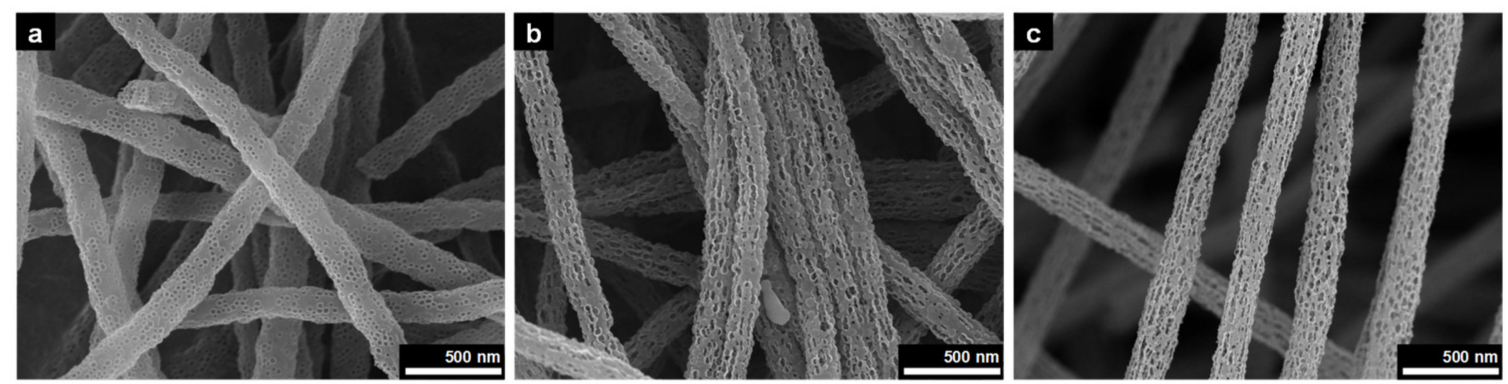

Figure 3. FE-SEM images of p-CNFs prepared by $8 \mathrm{wt} \%$ PAN dissolved in DMF solution with (a) 350 $\mathrm{wt} \%$, (b) $500 \mathrm{wt} \%$, and (c) $700 \mathrm{wt} \%$ silica nanoparticle contents (insets: cross-sectional SEM images, scale bars $=200 \mathrm{~nm}$ ).

Pore characteristics of $\mathrm{CNF}$ and $\mathrm{p}-\mathrm{CNF}$ were investigated using $\mathrm{N}_{2}$ sorption measurements. The specific surface area, micropore area, pore volume and pore size are summarized in Table 1 . The uniformly dispersed silica nanoparticles in the CNF offered numerous channels to interconnect with the micropores, leading to an increase in the surface area. As a result, the $\mathrm{p}-\mathrm{CNF}$ had a specific surface area of $391 \mathrm{~m}^{2} \mathrm{~g}^{-1}$, which isapproximately 1.8 times higher than that of $\mathrm{CNF}\left(214 \mathrm{~m}^{2} \mathrm{~g}^{-1}\right)$. The pore volume of $\mathrm{p}-\mathrm{CNF}$ determined by Barrett-Joyner-Halenda (BJH) pore size distribution was also larger than CNF. These observations are presumably due to pores that were formed after removal of the silica nanoparticles. 
Table 1. Pore characteristics of CNF and p-CNF.

\begin{tabular}{|c|c|c|c|c|}
\hline Samples & $\begin{array}{l}\text { Specific Surface } \\
\text { Area }^{1}\left(\mathrm{~m}^{2} / \mathrm{g}\right)\end{array}$ & $\begin{array}{c}\text { Micropore Area } \\
\left(\mathrm{m}^{2} / \mathrm{g}\right)\end{array}$ & $\begin{array}{l}\text { Pore Volume } \\
\quad\left(\mathrm{cm}^{2} / \mathrm{g}\right)\end{array}$ & Pore Size $^{1}(\mathrm{~nm})$ \\
\hline $\mathrm{CNF}$ & 214.19 & 198.74 & 0.118 & 2.218 \\
\hline $\mathrm{p}-\mathrm{CNF}$ & 391.43 & 260.22 & 0.987 & 10.088 \\
\hline
\end{tabular}

${ }^{1}$ These values are estimated by using the Brunauer-Emmett-Teller (BET) model. ${ }^{2}$ Estimated by $\mathrm{t}$-plot method. ${ }^{3}$ These values are estimated by using the Barrett-Joyner-Halenda (BJH) model.

Judging from these data, it can be concluded that the silica nanoparticles were successfully introduced into the CNF without any structural collapse. Furthermore, the interconnected pore structure of $\mathrm{p}-\mathrm{CNF}$ with a high surface area was expected to increase wettability of electrolyte, and thus enable them to be used as highly efficient electrode for ECs.

The electrochemical characterizations of $\mathrm{p}-\mathrm{CNF}$ and $\mathrm{CNF}$ electrodes were carried out by two-electrode cyclic voltammetry $(\mathrm{CV})$ and galvanostatic charge/discharge (GCD) tests over the voltage window of $1 \mathrm{~V}$ in $1.0 \mathrm{M} \mathrm{H}_{2} \mathrm{SO}_{4}$ aqueous electrolyte at room temperature. Figure 4a shows the CV curves of p-CNF and CNF electrodes, both of which retain nearly box-like curves even up to a high scan rate of $1000 \mathrm{mV} \mathrm{s}^{-1}$. This is indicative of excellent charge propagation across electrodes. Additionally, the current induced by charge accumulation for $\mathrm{p}-\mathrm{CNF}$ is significantly larger than that of $\mathrm{CNF}$ at a constant scan rate of $50 \mathrm{mV} \mathrm{s}^{-1}$ (Figure $4 \mathrm{~b}$ ). The corresponding areal capacitance is $38 \mathrm{mF}$ $\mathrm{cm}^{-2}, 37$-fold greater than $1.0 \mathrm{mF} \mathrm{cm}{ }^{-2}$ of CNF. This observation was supported by performing GCD measurements over the currents of 0.04 to $9.3 \mathrm{~mA} \mathrm{~cm}^{-2}$. A longer triangular GCD profile of $\mathrm{p}-\mathrm{CNT}$ electrode than that of a CNF electrode demonstrated that the former electrodes accumulated the larger amount of EDLs on the surface (Figure 4c). The areal capacitance of $\mathrm{p}-\mathrm{CNF}$ is $13 \mathrm{mF} \mathrm{cm}^{-2}, 38$-times larger than $0.34 \mathrm{mF} \mathrm{cm}^{-2}$ of $\mathrm{CNF}$, which was comparable to values of other state-of-the-art electrical double layer capacitor (EDLC) type electrodes reported [43-45]. Fast charge-discharge behavior within seconds was also observed, leading to high power capability. Rate-retention performance was obtained by calculating the discharge curve of the GCD (Figure 4d). The areal capacitance of $14 \mathrm{mF} \mathrm{cm}^{-2}$ for p-CNF at low current of $0.23 \mathrm{~mA} \mathrm{~cm}^{-2}$ was retained by $79 \%$ even at a large areal-based current of 9.3 $\mathrm{mA} \mathrm{cm}{ }^{-2}$, proving exceptional rate-retention capability.
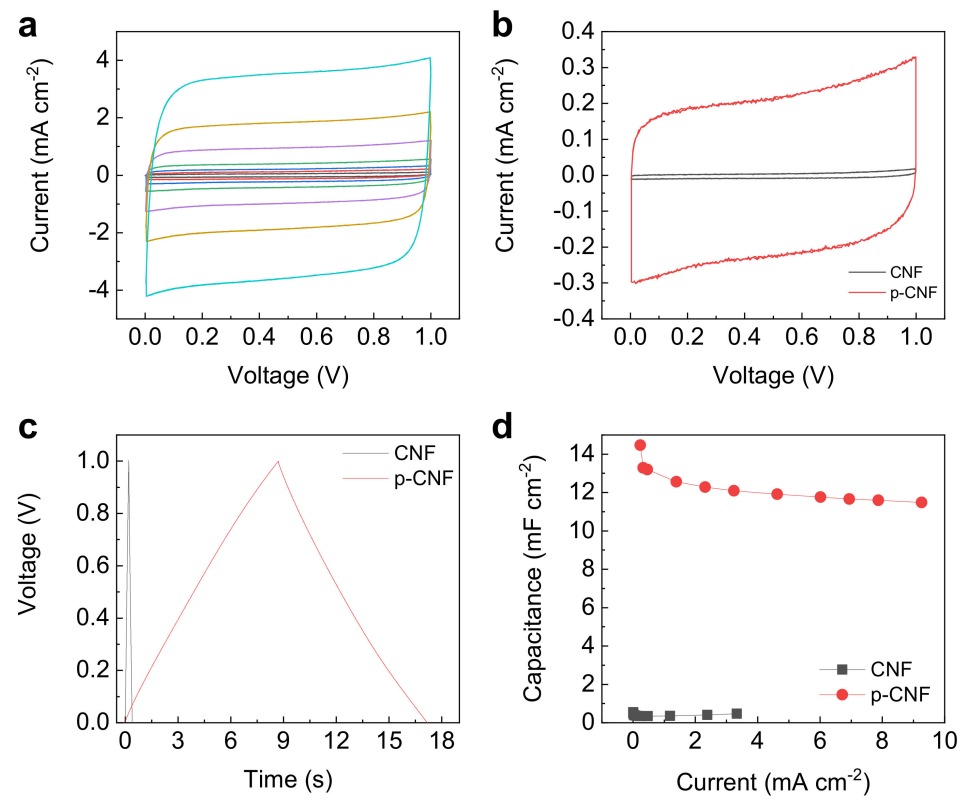

Figure 4. (a) Cyclic voltammetry (CV) curves of $\mathrm{p}-\mathrm{CNF}$ electrode at scan rates of 10 to $1000 \mathrm{mV} \mathrm{s}^{-1}$. (b) CV curves (at a constant scan rate of $50 \mathrm{mV} \mathrm{s}^{-1}$ ), (c) galvanostatic charge/discharge (GCD) profiles (at a constant current of $0.5 \mathrm{~mA} \mathrm{~cm}^{-2}$ ), and (d) rate-retention capability of CNF and p-CNF electrodes. 
The additional details of why $\mathrm{p}$-CNF exhibited better performance than CNF were identified through electrochemical impedance spectroscopy measurements over a frequency range of $10^{6}$ to $10^{-2} \mathrm{~Hz}$ (Figure 5). The intercept of the real part of the Nyquist plot was related to the equivalence series resistance (ESR) that was attributed to the combination of electrode and electrolyte resistances and contact resistance between the current collector and electrode. The ESR for $\mathrm{p}$-CNF was quite small, $3.0 \Omega$, close to $1.1 \Omega$ of $C N F$, which indicated that pore formation via a silica template did not aggravate the electrical property of $\mathrm{p}$-CNF. The intermediate frequency region of the Nyquist plots, i.e., $45^{\circ}$ Warburg region, exhibited the slope deviated from the vertical line of ideal resistor-capacitor (RC) circuit, attributed to the limited ion diffusion of the electrolyte [46]. The p-CNF electrodes displayed much shorter Warburg length than CNF electrodes, and demonstrated faster ion diffusion across electrode/electrolyte interface due to the porous pores in p-CNF [47,48]. The nonporous CNF electrode resulted in relatively longer Warburg length, reflecting slow ion kinetics. The more vertical slope of the p-CNF electrode than that of the CNF electrode in the low-frequency region indicated a purely capacitive behavior. With the results we observed, we can conclude that better electrochemical performances of the $\mathrm{p}$-CNF electrode than the neat CNF electrode were due to the electrode/electrolyte interface largely formed throughout the porous nanofiber electrodes.

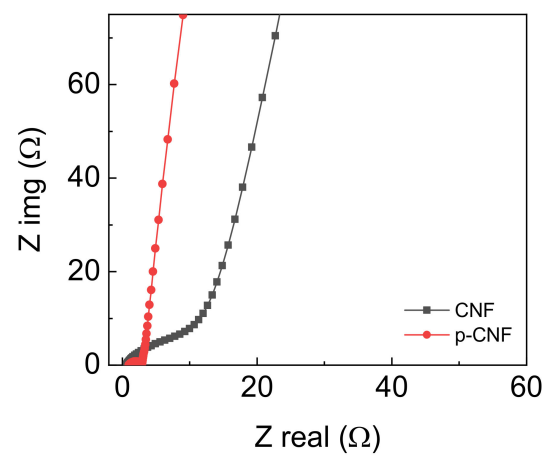

Figure 5. Nyquist plots of CNF and p-CNF electrodes.

Long-term cycle stability of the p-CNF electrode was confirmed over repeated 5000 GCD cycles at a constant current of $0.19 \mathrm{~mA} \mathrm{~cm}^{-2}$ (Figure 6). The electrode retained $\sim 98 \%$ of initial areal capacitance and nearly $100 \%$ of coulombic efficiency for at least 5000 GCD cycles, demonstrating good cycle stability.

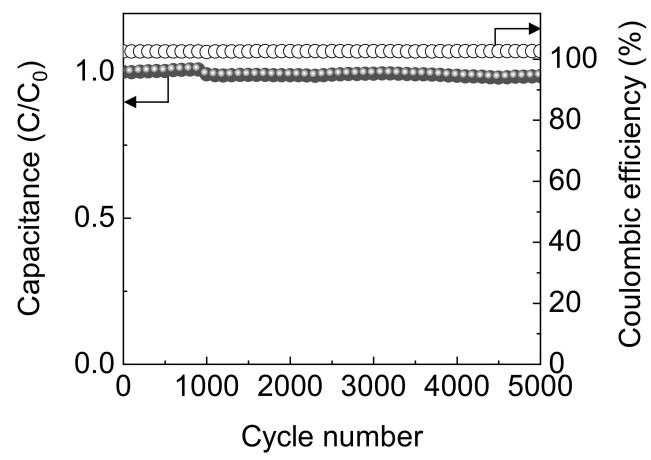

Figure 6. Long-term cycle stability and coulombic efficiency of p-CNF over 5000 GCD cycles at 0.19 $\mathrm{mA} \mathrm{cm}-2 . C_{0}$ is the initial capacitance and $C$ is the capacitance at the indicated number of cycles.

\section{Conclusions}

In conclusion, the present work demonstrated that the concept of porous carbon design holds great potential as an electrochemical energy storage. Starting from electrospun PAN/silica composites, $\mathrm{p}$-CNFs were formed via oxidation/carbonization and subsequent silica etching. The porosity of p-CNFs was modulated by a simple change of $w \mathrm{t} \%$ of PAN to silica nanoparticles. The optimum weight $\%$ was 
found to be $500 \mathrm{wt} \%$. Cyclic voltammetry and galvanostatic charge/discharge results demonstrated that $\mathrm{p}$-CNF electrodes revealed better electrochemical performances with respect to areal capacitance and rate performance than neat CNF electrodes. This relatively high-performance of $\mathrm{p}$-CNF was due to enhanced wettability of electrode by electrolyte through well-connected pores, synergistically improving the effective surface area of the electrode/electrolyte interface. Additionally, they exhibited exceptional long cycle lives and coulombic efficiency for at least 5000 charge/discharge cycles.

Author Contributions: Conceptualization and methodology, J.-Y.H. and S.-K.K.; investigation and data curation, J.K., Y.-J.H., J.-Y.H. and S.-K.K.; writing—original draft preparation, J.K., Y.-J.H., J.-Y.H. and S.-K.K.; writing—review and editing, J.-Y.H. and S.-K.K.; visualization, J.K., Y.-J.H.; supervision, J.-Y.H. and S.-K.K.; project administration, J.-Y.H. and S.-K.K., J.K. and Y.-J.H. contributed equally to this work. All authors have read and agreed to the published version of the manuscript.

Funding: This research received no external funding.

Acknowledgments: J.-Y.H. acknowledges the support from the Basic Science Research Program through the National Research Foundation of Korea (NRF) funded by the Ministry of Education (NRF-2017R1C1B2007153). This work was also supported by Basic Science Research Program through the National Research Foundation of Korea (NRF) funded by the Ministry of Education (NRF-2018R1D1A3B07048748).

Conflicts of Interest: The authors declare no conflict of interest.

\section{References}

1. Zhao, M.-Q.; Zhang, Q.; Huang, J.-Q.; Tian, G.-L.; Chen, T.-C.; Qian, W.-Z.; Wei, F. Towards high purity graphene/single-walled carbon nanotube hybrids with improved electrochemical capacitive performance. Carbon 2013, 54, 403-411. [CrossRef]

2. Vangari, M.; Pryor, T.; Jiang, L. Supercapacitors: Review of materials and fabrication methods. J. Energy Eng. 2013, 139, 72-79. [CrossRef]

3. Guo, Q.; Zhou, X.; Li, X.; Chen, S.; Seema, A.; Greiner, A.; Hou, H. Supercapacitors based on hybrid carbon nanofibers containing multiwalled carbon nanotubes. J. Mater. Chem. 2009, 19, 2810-2816. [CrossRef]

4. Wang, K.; Wang, Y.; Wang, Y.; Hosono, E.; Zhou, H. Mesoporous carbon nanofibers for supercapacitor application. J. Phys. Chem. C 2009, 113, 1093-1097. [CrossRef]

5. Yu, D.; Zhai, S.; Jiang, W.; Goh, K.; Wei, L.; Chen, X.; Jiang, R.; Chen, Y. Transforming pristine carbon fiber tows into high performance solid-state fiber supercapacitors. Adv. Mater. 2015, 27, 4895-4901. [CrossRef] [PubMed]

6. Simon, P.; Gogotsi, Y. Materials for electrochemical capacitors. Nat. Mater. 2008, 7, 845-854. [CrossRef] [PubMed]

7. Qu, G.; Cheng, J.; Li, X.; Yuan, D.; Chen, P.; Chen, X.; Wang, B.; Peng, H. A fiber supercapacitor with high energy density based on hollow graphene/conducting polymer fiber electrode. Adv. Mater. 2016, 28, 3646-3652. [CrossRef]

8. Liu, C.; Yu, Z.; Neff, D.; Zhamu, A.; Jang, B.Z. Graphene-based supercapacitor with an ultrahigh energy density. Nano Lett. 2010, 10, 4863-4868. [CrossRef]

9. El-Kady, M.F.; Ihns, M.; Li, M.; Hwang, J.Y.; Mousavi, M.F.; Chaney, L.; Lech, A.T.; Kaner, R.B. Engineering three-dimensional hybrid supercapacitors and microsupercapacitors for high-performance integrated energy storage. Proc. Natl. Acad. Sci. USA 2015, 112, 4233. [CrossRef]

10. Chen, T.; Dai, L. Flexible supercapacitors based on carbon nanomaterials. J. Mater. Chem. A 2014, 2, 10756-10775. [CrossRef]

11. Shi, Z.; Chu, W.; Hou, Y.; Gao, Y.; Yang, N. Asymmetric supercapacitors with high energy densities. Nanoscale 2019, 11, 11946-11955. [CrossRef] [PubMed]

12. Tahir, M.; He, L.; Haider, W.A.; Yang, W.; Hong, X.; Guo, Y.; Pan, X.; Tang, H.; Li, Y.; Mai, L. Co-electrodeposited porous PEDOT-CNT microelectrodes for integrated micro-supercapacitors with high energy density, high rate capability, and long cycling life. Nanoscale 2019, 11, 7761-7770. [CrossRef] [PubMed]

13. Chen, L.-F.; Zhang, X.-D.; Liang, H.-W.; Kong, M.; Guan, Q.-F.; Chen, P.; Wu, Z.-Y.; Yu, S.-H. Synthesis of nitrogen-doped porous carbon nanofibers as an efficient electrode material for supercapacitors. ACS Nano 2012, 6, 7092-7102. [CrossRef] 
14. Qin, K.; Kang, J.; Li, J.; Shi, C.; Li, Y.; Qiao, Z.; Zhao, N. Free-standing porous carbon nanofiber/ultrathin graphite hybrid for flexible solid-state supercapacitors. ACS Nano 2015, 9, 481-487. [CrossRef]

15. Zhang, X.; Shi, W.; Zhu, J.; Zhao, W.; Ma, J.; Mhaisalkar, S.; Maria, T.L.; Yang, Y.; Zhang, H.; Hng, H.H.; et al. Synthesis of porous $\mathrm{NiO}$ nanocrystals with controllable surface area and their application as supercapacitor electrodes. Nano Res. 2010, 3, 643-652. [CrossRef]

16. He, X.; Zhao, N.; Qiu, J.; Xiao, N.; Yu, M.; Yu, C.; Zhang, X.; Zheng, M. Synthesis of hierarchical porous carbons for supercapacitors from coal tar pitch with nano- $\mathrm{Fe}_{2} \mathrm{O}_{3}$ as template and activation agent coupled with $\mathrm{KOH}$ activation. J. Mater. Chem. A 2013, 1, 9440-9448. [CrossRef]

17. Qie, L.; Chen, W.; Xu, H.; Xiong, X.; Jiang, Y.; Zou, F.; Hu, X.; Xin, Y.; Zhang, Z.; Huang, Y. Synthesis of functionalized 3D hierarchical porous carbon for high-performance supercapacitors. Energy Environ. Sci. 2013, 6, 2497-2504. [CrossRef]

18. Shi, Y.; Pan, L.; Liu, B.; Wang, Y.; Cui, Y.; Bao, Z.; Yu, G. Nanostructured conductive polypyrrole hydrogels as high-performance, flexible supercapacitor electrodes. J. Mater. Chem. A 2014, 2, 6086-6091. [CrossRef]

19. Choi, B.G.; Yang, M.; Hong, W.H.; Choi, J.W.; Huh, Y.S. 3D Macroporous graphene frameworks for supercapacitors with high energy and power densities. ACS Nano 2012, 6, 4020-4028. [CrossRef]

20. Song, S.; Ma, F.; Wu, G.; Ma, D.; Geng, W.; Wan, J. Facile self-templating large scale preparation of biomass-derived 3D hierarchical porous carbon for advanced supercapacitors. J. Mater. Chem. A 2015, 3, 18154-18162. [CrossRef]

21. Yu, B.; Kuang, D.; Liu, S.; Liu, C.; Zhang, T. Template-assisted self-assembly method to prepare three-dimensional reduced graphene oxide for dopamine sensing. Sens. Actuator B-Chem. 2014, 205, 120-126. [CrossRef]

22. Xing, Z.; Geng, B.; Li, X.; Jiang, H.; Feng, C.; Ge, T. Self-assembly fabrication of 3D porous quasi-flower-like $\mathrm{ZnO}$ nanostrip clusters for photodegradation of an organic dye with high performance. CrystEngComm 2011, 13, 2137-2142. [CrossRef]

23. Jeon, Y.S.; Kim, S.H.; Park, B.C.; Nam, D.Y.; Kim, Y.K. Synthesis of Co nanotubes by nanoporous template-assisted electrodeposition via the incorporation of vanadyl ions. ChemComm 2017, 53, 1825-1828. [CrossRef] [PubMed]

24. Dubal, D.P.; Holze, R.; Kulal, P.M. Enhanced supercapacitive performances of hierarchical porous nanostructure assembled from ultrathin $\mathrm{MnO}_{2}$ nanoflakes. J. Mater. Sci. 2013, 48, 714-719. [CrossRef]

25. Luo, Y.; Jiang, J.; Zhou, W.; Yang, H.; Luo, J.; Qi, X.; Zhang, H.; Yu, D.Y.W.; Li, C.M.; Yu, T. Self-assembly of well-ordered whisker-like manganese oxide arrays on carbon fiber paper and its application as electrode material for supercapacitors. J. Mater. Chem. 2012, 22, 8634-8640. [CrossRef]

26. Ma, G.; Yan, X.; Li, Y.; Xiao, L.; Huang, Z.; Lu, Y.; Fan, J. Ordered nanoporous silica with periodic 30-60 nm pores as an effective support for gold nanoparticle catalysts with enhanced lifetime. J. Am. Chem. Soc. 2010, 132, 9596-9597. [CrossRef]

27. Yin, Y.; Liu, C.; Fan, S. Well-constructed CNT mesh/PANI nanoporous electrode and its thickness effect on the supercapacitor properties. J. Phys. Chem. C 2012, 116, 26185-26189. [CrossRef]

28. Fan, W.; Miao, Y.-E.; Huang, Y.; Tjiu, W.W.; Liu, T. Flexible free-standing 3D porous N-doped graphene-carbon nanotube hybrid paper for high-performance supercapacitors. RSC Adv. 2015, 5, 9228-9236. [CrossRef]

29. Wang, Q.; Yan, J.; Wang, Y.; Wei, T.; Zhang, M.; Jing, X.; Fan, Z. Three-dimensional flower-like and hierarchical porous carbon materials as high-rate performance electrodes for supercapacitors. Carbon 2014, 67, 119-127. [CrossRef]

30. Wang, D.-W.; Li, F.; Fang, H.-T.; Liu, M.; Lu, G.-Q.; Cheng, H.-M. Effect of pore packing defects in 2-D ordered mesoporous carbons on ionic transport. J. Phys. Chem. B 2006, 110, 8570-8575. [CrossRef]

31. Wang, D.-W.; Li, F.; Liu, M.; Lu, G.Q.; Cheng, H.-M. 3D aperiodic hierarchical porous graphitic carbon material for high-rate electrochemical capacitive energy storage. Angew. Chem. Int. Ed. 2008, 47, 373-376. [CrossRef] [PubMed]

32. Yoon, S.; Lee, J.; Hyeon, T.; Oh, S.M. Electric double-layer capacitor performance of a new mesoporous carbon. J. Electrochem. Soc. 2000, 147, 2507-2512. [CrossRef]

33. Na, W.; Jun, J.; Park, J.W.; Lee, G.; Jang, J. Highly porous carbon nanofibers co-doped with fluorine and nitrogen for outstanding supercapacitor performance. J. Mater. Chem. A 2017, 5, 17379-17387. [CrossRef] 
34. Ling, Z.; Wang, Z.; Zhang, M.; Yu, C.; Wang, G.; Dong, Y.; Liu, S.; Wang, Y.; Qiu, J. Sustainable synthesis and assembly of biomass-derived $\mathrm{B} / \mathrm{N}$ co-doped carbon nanosheets with ultrahigh aspect ratio for high-performance supercapacitors. Adv. Funct. Mater. 2016, 26, 111-119. [CrossRef]

35. Zhang, G.; Song, Y.; Zhang, H.; Xu, J.; Duan, H.; Liu, J. Radially aligned porous carbon nanotube arrays on carbon fibers: A hierarchical 3D carbon nanostructure for high-performance capacitive energy storage. Adv. Funct. Mater. 2016, 26, 3012-3020. [CrossRef]

36. Yanilmaz, M.; Dirican, M.; Asiri, A.M.; Zhang, X. Flexible polyaniline-carbon nanofiber supercapacitor electrodes. J. Energy Storage 2019, 24, 100766. [CrossRef]

37. Ambade, R.B.; Ambade, S.B.; Shrestha, N.K.; Salunkhe, R.R.; Lee, W.; Bagde, S.S.; Kim, J.H.; Stadler, F.J.; Yamauchi, Y.; Lee, S.-H. Controlled growth of polythiophene nanofibers in $\mathrm{TiO}_{2}$ nanotube arrays for supercapacitor applications. J. Mater. Chem. A 2017, 5, 172-180. [CrossRef]

38. Duy, L.X.; Peng, Z.; Li, Y.; Zhang, J.; Ji, Y.; Tour, J.M. Laser-induced graphene fibers. Carbon 2018, 126, $472-479$. [CrossRef]

39. Almuhamed, S.; Khenoussi, N.; Bonne, M.; Schacher, L.; Lebeau, B.; Adolphe, D.; Brendlé, J. Electrospinning of PAN nanofibers incorporating SBA-15-type ordered mesoporous silica particles. Eur. Polym. J. 2014, 54, 71-78. [CrossRef]

40. Wu, Q.-Y.; Liang, H.-Q.; Li, M.; Liu, B.-T.; Xu, Z.-K. Hierarchically porous carbon membranes derived from PAN and their selective adsorption of organic dyes. Chin. J. Polym. Sci. 2016, 34, 23-33. [CrossRef]

41. Jiang, H.; Lee, P.S.; Li, C. 3D carbon based nanostructures for advanced supercapacitors. Energy Environ. Sci. 2013, 6, 41-53. [CrossRef]

42. Stöber, W.; Fink, A.; Bohn, E. Controlled growth of monodisperse silica spheres in the micron size range. J. Colloid Interface Sci. 1968, 26, 62-69. [CrossRef]

43. Lekakou, C.; Moudam, O.; Markoulidis, F.; Andrews, T.; Watts, J.F.; Reed, G.T. Carbon-based fibrous EDLC capacitors and supercapacitors. J. Nanotechnol. 2011, 2011, 409382. [CrossRef]

44. Huang, P.; Heon, M.; Pech, D.; Brunet, M.; Taberna, P.-L.; Gogotsi, Y.; Lofland, S.; Hettinger, J.D.; Simon, P. Micro-supercapacitors from carbide derived carbon (CDC) films on silicon chips. J. Power Sources 2013, 225, 240-244. [CrossRef]

45. Yu, D.; Qian, Q.; Wei, L.; Jiang, W.; Goh, K.; Wei, J.; Zhang, J.; Chen, Y. Emergence of fiber supercapacitors. Chem. Soc. Rev. 2015, 44, 647-662. [CrossRef] [PubMed]

46. Mei, B.-A.; Munteshari, O.; Lau, J.; Dunn, B.; Pilon, L. Physical interpretations of Nyquist plots for EDLC electrodes and devices. J. Phys. Chem. C 2018, 122, 194-206. [CrossRef]

47. Lu, W.; Qu, L.; Henry, K.; Dai, L. High performance electrochemical capacitors from aligned carbon nanotube electrodes and ionic liquid electrolytes. J. Power Sources 2009, 189, 1270-1277. [CrossRef]

48. Weng, Z.; Su, Y.; Wang, D.-W.; Li, F.; Du, J.; Cheng, H.-M. Graphene-cellulose paper flexible supercapacitors. Adv. Energy Mater. 2011, 1, 917-922. [CrossRef]

(C) 2020 by the authors. Licensee MDPI, Basel, Switzerland. This article is an open access article distributed under the terms and conditions of the Creative Commons Attribution (CC BY) license (http://creativecommons.org/licenses/by/4.0/). 